\title{
BOEKBESPREKING: LA PEINTURE CHINOISE
}

Vrijwel onopgemerkt in de rest van de wereld is in Frankrijk een bijzonder en vernieuwend boek over de Chinese schilderkunst verschenen. Het is allereerst bijzonder omdat het een overzicht geeft van de Chinese kunst aan de hand van schilderijen die voor tachtig procent afkomstig zijn uit Chinese musea, vele voor de eerste maal in het Westen gepubliceerd. Het boek is bovendien vernieuwend omdat het niet het gebruikelijke historische overzicht geeft van de Chinese schilderkunst, maar een thematische indeling naar onderwerpen. Het is ook het vermelden waard dat het volumineuze boek door twee jonge wetenschappers is geschreven (beiden onder de veertig jaar volgens het voorwoord) die hun opleiding in de Chinese kunst niet in het Westen hebben genoten, maar aan de kunstacademie van Beijing. Hun combinatie van kennis en expertise ligt ten grondslag aan het succesvolle resultaat: een werk dat niet alleen de laatste inzichten in de Chinese schilderkunst uit het Westen, (lees: Noord-Amerika) presenteert, maar ook uit China en Frankrijk, twee landen die in de laatste decennia een sterke traditie in onderzoek naar Chinese kunst hebben opgebouwd, in China veelal aan de hand van nieuwe archeologische vondsten en in Frankrijk naar aanleiding van de vele exposities over Chinese kunst die bijna jaarlijks in Parijs gehouden worden.

Het boek is rijk geillustreerd en de reproducties van de schilderijen zijn van bijzonder hoge kwaliteit. Vanwege de kwaliteit van de afbeeldingen en doordat het merendeel van de schilderijen niet bekend is bij het grote publiek, in het bijzonder de muurschilderingen uit graftombes en tempels, is het een zeer waardevolle aanwinst voor elke liefhebber van Chinese schilderkunst.

De schilderijen zijn georganiseerd naar een tiental thema's die de basis vormen voor de indeling in tien hoofdstukken: 1) Confucianistische toonbeelden van de vijf sociale relaties; 2) Het portret; 3) Portretten van vrouwen; 4) Zedenschilderijen; 5) Religieuze schilderkunst; 6) Narratieve en literaire schilderkunst; 7) Landschapsschilderkunst; 8) De schilderkunst van de literaten; 9) Bloemen en vogels; en 10) Schilderijen van dieren. Na de hoofdstukken volgt nog een appendix met vertalingen van enkele belangrijke klassieke teksten over schilderkunst, een chronologie, een landkaart van China, een uitstekend notenapparaat, bibliografie en een namenindex. Het is noemenswaardig dat alle Chinese namen en termen in de tekst ook voorzien zijn van Chinese karakters.

Elk hoofdstuk is ingedeeld naar verschillende thema's en geïllustreerd met schilderijen, zonder dat daarbij belangrijke historische ontwikkelingen binnen de Chinese schilderkunst overgeslagen worden. Er vindt soms enige mate van overlap plaats, zoals bij de eerste drie hoofdstukken die alle over portretten gaan, maar het belang van het thema in het oude China (de confucianistische ${ }_{2 \mathrm{PM}}$ toonbeelden) of in de hedendaagse visie op kunst (portretten van vróưwen) ${ }^{\text {access }}$ 
Afbeelding 1

Anoniem, De gitaarspeelster, 15e-16e eeuw. Inkt en pigment op zijde, 121 x 69,3 cm. Provincie Museum te Shenyang. La peinture chinoise, p. 103.

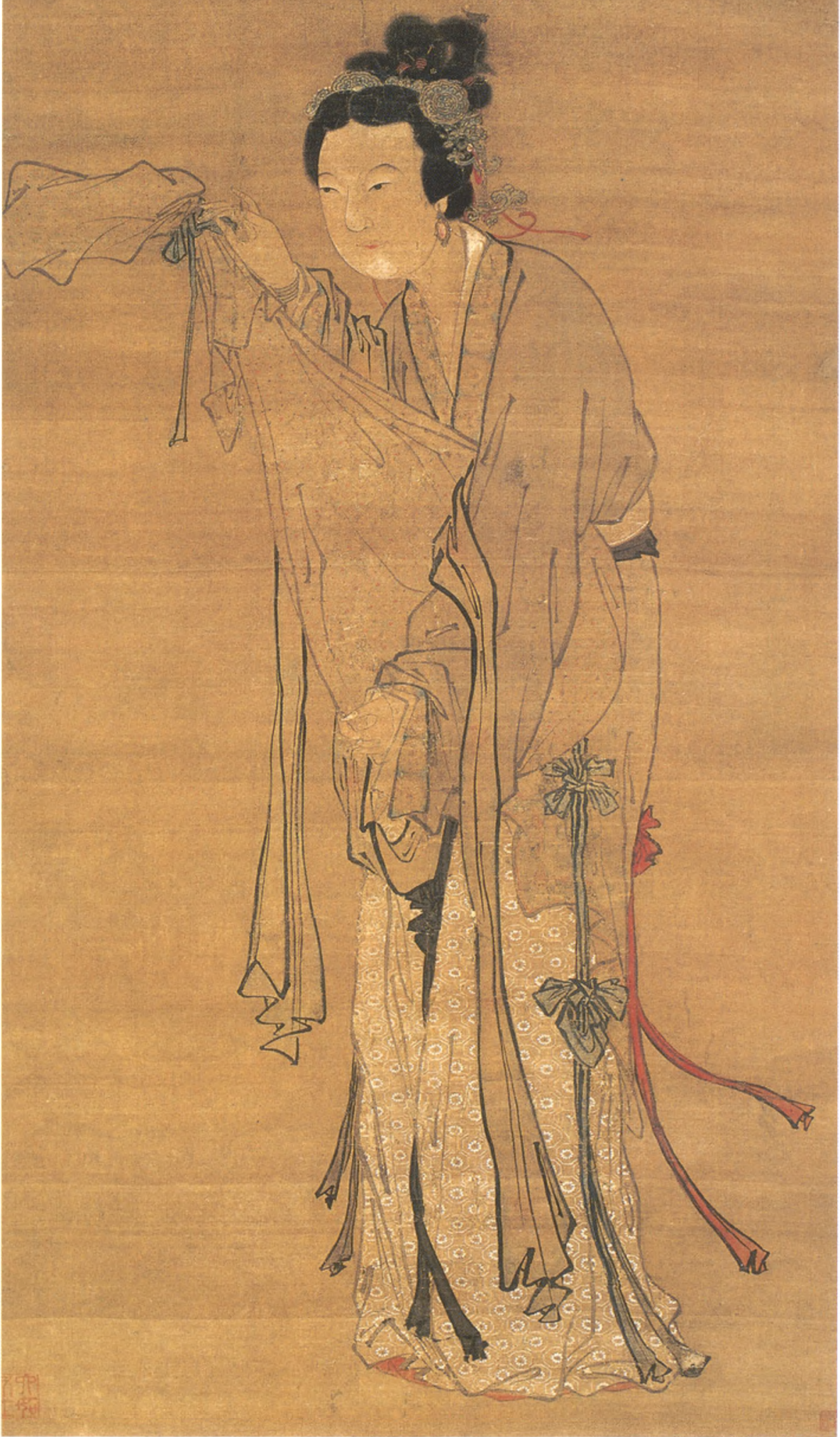

Downloaded from Brill.com@4/26/2023 02:01:32PM 
maken het interessant om deze thema's apart toe te lichten. Ook komt het vaak voor dat een schilder actief was in meer dan één thema en deze naam verschijnt dan op verschillende plaatsen in het boek. De auteurs weten dit echter kundig te presenteren zonder in storende herhalingen te vallen. De auteurs hebben de hoofdstukken niet samen geschreven maar zijn elk verantwoordelijk voor vijf verschillende hoofdstukken (Lesbre hoofdstukken 1, 2, 3, 5, 8; Liu hoofdstukken 4, 6, 7, 9, 10). Laat mij kort de inhoud van elk hoofdstuk bespreken voordat ik enkele punten van discussie naar voren breng.

Het eerste hoofdstuk, De confucianistische toonbeelden, behandelt de vijf maximes van confucianistische deugd: kinderlijke piëteit (xiao), loyaliteit (zhong), betrouwbaarheid (xin), volgzaamheid (shun) en medemenselijkheid (ren). Deze thema's waren erg populair in de vroege Chinese Middeleeuwen en moesten de sociale verplichtingen van kinderen tegenover hun ouders of voorouders, ambtenaren tegenover hun heerser en vrouwen tegenover hun mannen of zonen benadrukken. Ze hadden hoofdzakelijk een didactische functie, waarbij de toeschouwer geïnspireerd moest raken tot goed gedrag door schilderingen van exemplarische figuren, zowel uiterst goede als uiterst slechte.

Het tweede hoofdstuk, Het portret, behandelt een zeer uiteenlopende reeks thema's rond het afbeelden van mensen. Ten eerste wordt het probleem van de gelijkenis behandeld, van zowel levende als overleden mensen (voorouders), waarbij in China de normatieve afbeelding belangrijker is dan een weergave van de realiteit. Verder komen thema's als grafschilderingen, portretten van keizers, koningen en exemplarische ministers, buitenlandse gezanten, de 'ongebonden literaten', mannen in vrouwelijk gezelschap aan de orde, alsook de invloed van Westers illusionisme op Chinese portretkunst. Het derde hoofdstuk, Het portret van vrouwen, is een doordachte verhandeling over portretten van Chinese vrouwen gezien als schoonheidsideaal, afgebeeld in de keizerlijke vrouwenvertrekken of als objecten van historische puurheid, natuurlijk altijd gezien vanuit en door het oog van de mannelijke toeschouwer. Soms levert het mooie resultaten op. Een anoniem schilderij van een musicienne uit de $15^{e}$ of $16^{e}$ eeuw is een uitstekend voorbeeld van de discrepantie tussen werkelijkheid en schoonheidsideaal voor de Chinese vrouw: een vrouw met gekromde rug alsof zij gebukt gaat onder een zware last, houdt onder haar arm een luit die nog ingepakt zit, een symbool van haar ongebruikte talenten (afb. 1). Deze Chinese schilder, als het geen vrouw was, stond duidelijk sympathiek tegenover zijn onderwerp.

Het vierde hoofdstuk, Zedenschilderkunst, geeft een klein overzicht van enkele belangrijke thema's uit het dagelijkse leven: afbeeldingen van banketten en feesten in de vroege Chinese schilderkunst, de lange rolschilderingen over het stadsleven (de beroemde Qingming shanghe tu 'Stroomopwaarts tijdens het lentefeest' en haar nazaten), kinderen, tempelfeesten, arbeiders, zwervers, lenteplaatjes, en rituele schilderingen van bijvoorbeeld Zhong Kui, een populaire demonenverdelger, zoals die gebruikt werden bij festivals. Het vijfde hoofdstuk, De religieuze schilderkunst, geeft eerst een korte inleiding in de drie belangrijkste religies van China, het confucianisme, het daoïsme en het boeddhisme. In de rest van het hoofdstuk wordt vervolgens aandacht besteed aan de schilderkunst van het boeddhisme zoals de muurschilderingen die belangrijke gebeurtenissen uit het leven van de Boeddha uitbeelden, hellen, paradijzen en hun goden, het westelijke paradijs 2 of 3 het : 01 : 32PM Pure Land waarin de negen gradaties van wedergeboorten op hiërarchische ${ }^{\text {access }}$ 


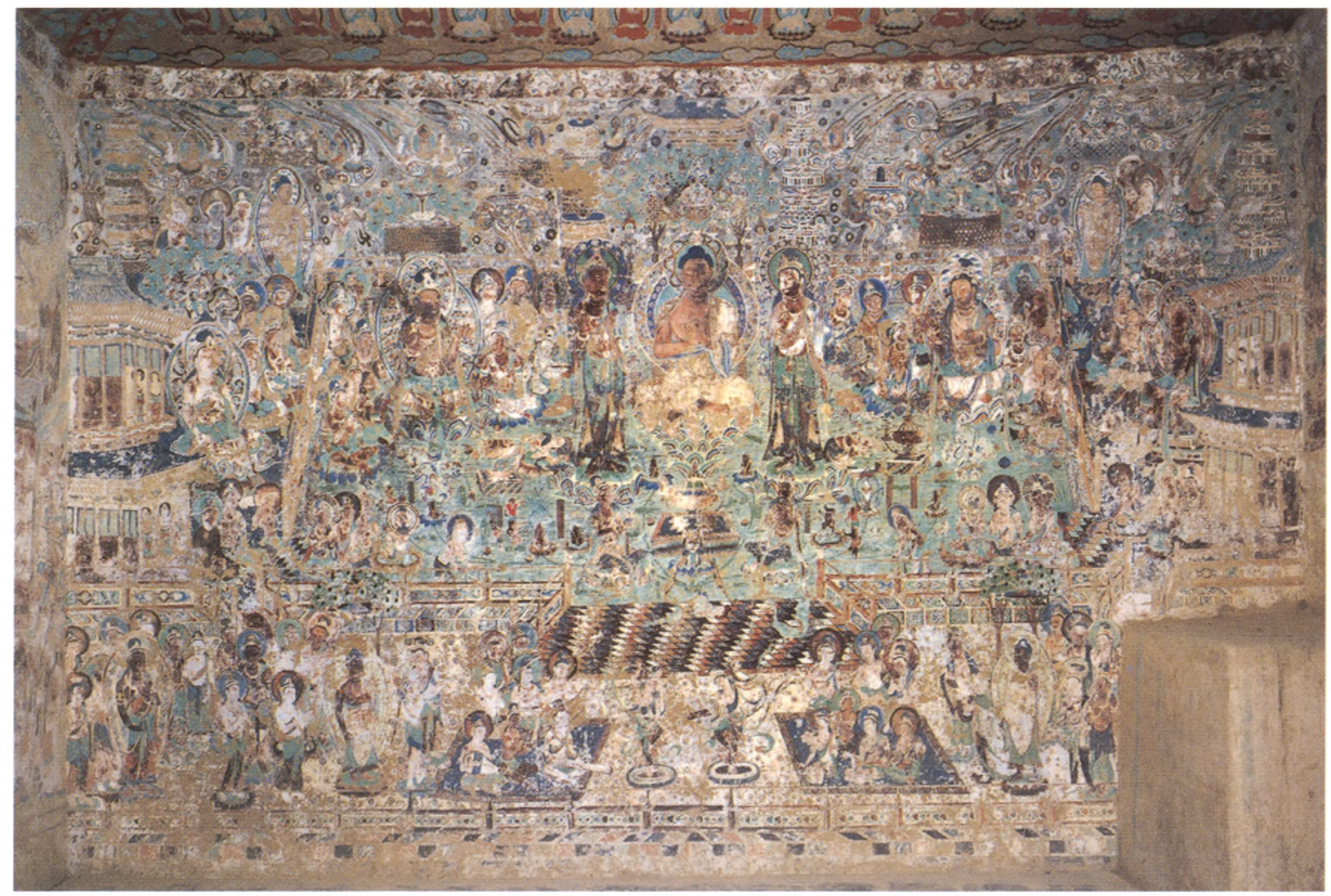

Afbeelding 2 Het Westelijk Paradijs van Amitabha Boeddha, 642. Muurschildering in grot nr. 220 te Dunhuang, provincie Gansu. La peinture chinoise, p. 212. afstand van de Boeddha worden afgebeeld (afb. 2). Ten slotte volgen afbeeldingen van bodhisattvas en arhats, de beschermheiligen van de boeddhistische leer.

Het zesde hoofdstuk, De narratieve en literaire schilderkunst, behandelt schilderijen die een bekend verhaal, historische passage, of gedicht uitbeelden.

Het zevende hoofdstuk, De landschapsschilderkunst, is vergeleken met de overige hoofdstukken niet alleen het langste, maar ook - een beetje teleurstellend - het enige hoofdstuk dat een volledig chronologische opsomming geeft. Het geeft op zeer gedegen wijze en geheel volgens de laatste ontwikkelingen op dit gebied een overzicht van de stijlontwikkeling van de vroege middeleeuwen tot de twintigste eeuw, waarin elke belangrijke gebeurtenis, school, innovatie en belangrijk persoon zijn opgenomen. Het achtste hoofdstuk, De schilderkunst van de literaten, behandelt de picturale kunstuitingen van de geletterde bovenlaag van de Chinese maatschappij. Literatenkunst wordt allereerst gepresenteerd als een art de vivre, waarbij verschillende onderwerpen uit hun leven in beeld worden gebracht. Voorbeelden hiervan zijn het wandelen in de bergen, citer spelen, met vrienden gedichten componeren, kalligrafieën van vroege meesters bekijken, en kunstcollecties van bevriende connaisseurs evalueren. Een ander typisch literatenthema zijn de emblematische onderwerpendie een gecodeerde $02: 01: 32 \mathrm{pm}$ betekenis hebben die alleen door ingewijden wordt begrepen zoals via free access 
schilderijen van buffels of paarden, pijnbomen, bamboe, prunus en wilde orchideeën. De literaten waren verantwoordelijk voor codificatie van de techniek, het 'inktspel', waarbij kleuren werden afgeschaft en een synthese plaatsvond tussen schilderkunst en kalligrafie. Ook ontwikkelden zij de kunstkritiek, uitgedrukt in de vele colofons die aan een schilderij werden toegevoegd.

Het negende hoofdstuk, Bloemen en vogels, is onderverdeeld in twee delen. In het eerste deel worden bloemen en vogels natuurgetrouw afgebeeld, een kunstvorm die ver teruggaat tot het Neolithicum en teruggevonden wordt op beschilderd aardewerk. In het tweede deel worden bloemen en vogels expressief uitgebeeld (xieyi), dat wil zeggen als uiting van individuele gevoelens. Deze laatste vorm werd eigenlijk pas vanaf de Ming-dynastie (1368-1644) populair en zette zich met name af tegen de academische stijl zoals die door het hof werd gepromoot en die - volgens de expressieve schilders - teveel nadruk legde op detail.

Het tiende en laatste hoofdstuk, Schilderijen van dieren, lijkt geen apart hoofdstuk maar is zeker een van de oudste thema's in de Chinese schilderkunst. Het omvat niet alleen de gangbare dieren zoals paarden, buffels, konijnen en vissen, maar ook al heel vroeg draken, eenhoorns, feniksen, en andere mythologische wezens. Een vrij on-Chinees aandoend schilderij uit de Yuan-dynastie (1260-1368) of eerder is een bijzondere exponent van deze traditie (afb. 3). Het stelt een volwassen hert voor dat wordt uitgedaagd door een jong hert dat het duidelijk op zijn reeën heeft voorzien. De voorstelling bestaat verder geheel uit kleurrijk gebladerte en struiken.

Een groot en rijk geïllustreerd boek als La peinture chinoise zou een goede aanleiding kunnen zijn tot een uitvoerige discussie en kritiek, maar ik zou mij graag willen beperken tot twee punten die mij essentieel lijken. Ten eerste de thematische aanpak, vooral in vergelijking met eerdere verschenen werken over Chinese schilderkunst. Ten tweede de vraag wat de auteurs niet beschrijven, of - anders gezegd - wat de auteurs blijkbaar niet definiëren als Chinese schilderkunst.

\section{Thematische aanpak}

Voor zover mij bekend, is La peinture chinoise het eerste grote album over Chinese schilderkunst met een thematische indeling. Dit mag een revolutie betekenen en zal hopelijk een nieuw tijdperk inluiden in de manier waarop Chinese schilderkunst gepresenteerd wordt en daarmee gezien, geapprecieerd en bestudeerd. Vooralsnog is de studie van de Chinese schilderkunst gedomineerd door Engelstalige producties waarbij geleerden uit NoordAmerika het voortouw nemen. Onderzoek beperkt zich ook met name tot collecties in Noord-Amerikaanse musea en het Paleis Museum in Taibei, Taiwan, waarbij bijna standaard een chronologisch historische methodologie wordt gehanteerd. In deze werken ligt de nadruk bijna zonder uitzondering op de literatenkunst in al haar facetten, ten koste van de 'professionele' kunst met wie zij een schijnbaar onverenigbaar dualisme vormt. Er zijn inmiddels vijf grote albums over de Chinese schilderkunst in de Engelse taal verschenen: Eight Dynasties of Chinese Painting (1980) beschrijft de collecties van de Nelson Gallery - Atkins Museum, Kansas City, en The Cleveland Museum of Art; Beyond Representation: Chinese Painting and Calligraphy $8^{\text {th }} / 2$ 164th cent: $01: 32 \mathrm{PM}$ (1992) behandelt schilderijen in de collectie van het Metropolitan Miùseurm in ${ }^{\text {ces }}$ 
Afbeelding 3

Anoniem, Herten in een bos tijdens de herfst, Yuan-dynastie (12601368). Inkt en pigment op zijde, $118,5 \times 64,6$ cm. Nationaal Paleismuseum te Taibei. La peinture chinoise, p. 445.

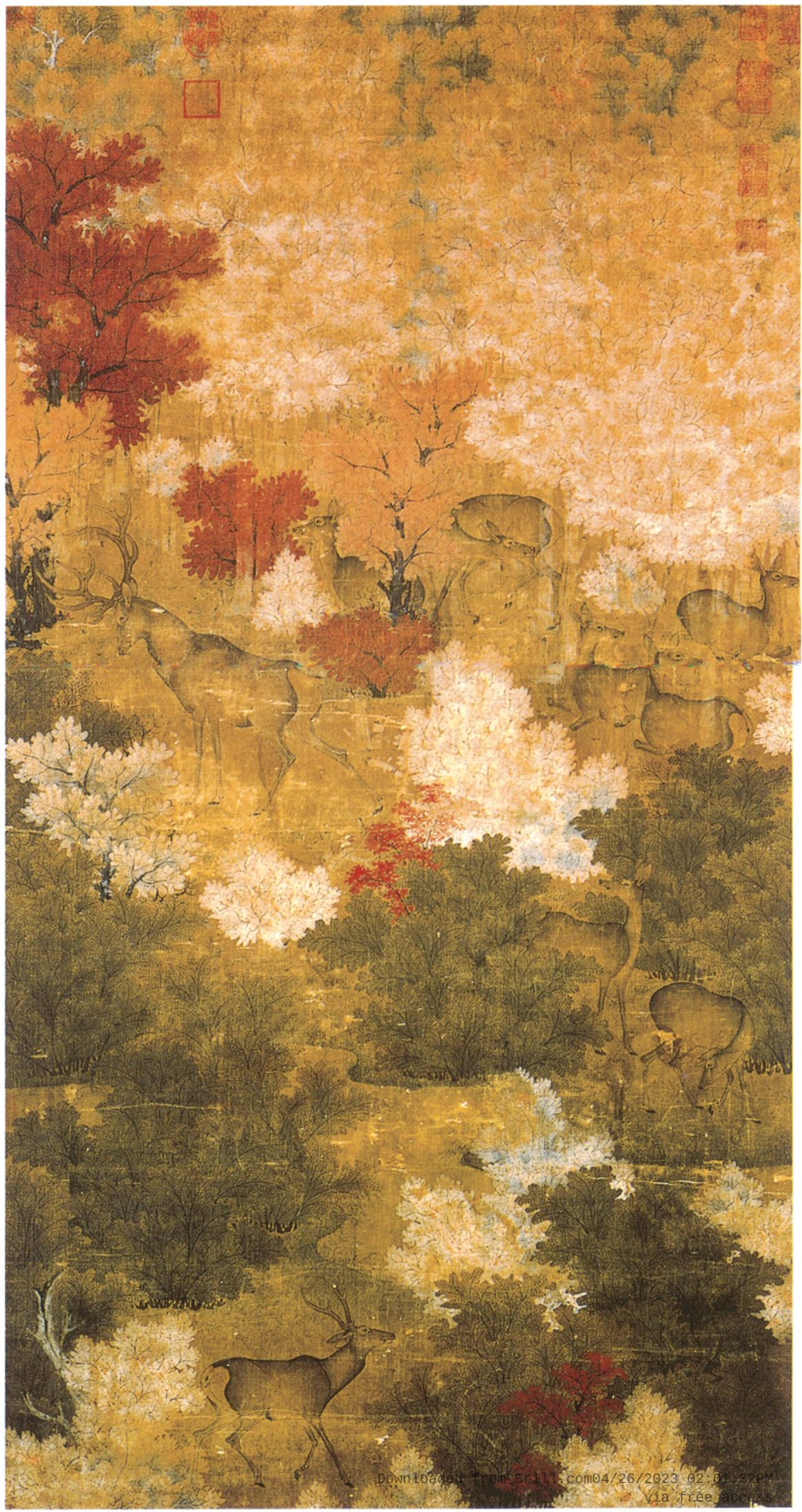


New York; Possessing the Past (1996) is een uitvoerige beschrijving van de grootste collectie Chinese schilderkunst op aarde, de voormalige keizerlijke collectie in het Paleis Museum in Taibei, Taiwan; en Tales from the Land of the Dragons: 1,000 Years of Chinese Painting (1997) is een historisch ingedeelde catalogus van de collectie Chinese schilderijen in het Museum of Fine Arts, Boston. Een uitzondering op de regel is Three Thousand Years of Chinese Painting (1997), misschien als antwoord op het monolithische Possessing the Past, dat wel nog steeds een historische indeling volgt maar voor het eerst ruim uit collecties van verschillende musea put om de geschiedenis van de Chinese schilderkunst te illustreren. In hun totaliteit vertegenwoordigen deze vijf albums het summum, de masterpieces, van de Chinese schilderkunst. Ze zijn geschreven voor een breed publiek, bekend over de hele wereld en zij bepalen daardoor in grote mate hoe naar Chinese kunst wordt gekeken. Dezelfde boeken zijn ook belangrijke referentiewerken voor studenten van Chinese kunst en worden vaak gebruikt als inleiding of lesmateriaal voor colleges over Chinese schilderkunst. Stuk voor stuk zijn deze werken natuurlijk mijlpalen in het onderzoek naar de Chinese schilderkunst en hebben zij een niet onbelangrijke bijdrage geleverd aan de verbreiding en waardering ervan.

De aanpak van deze werken heeft echter twee belangrijke consequenties. De eerste is dat een chronologisch historische indeling bijna onherroepelijk leidt tot een stijlgeschiedenis. In concrete zin betekent dit dat een geschiedenis van de schilderkunst herleid wordt tot een geschiedenis van biografieën van schilders. Veranderingen in stijl zouden verder te herleiden zijn tot veranderingen in de Zeitgeist van een bepaalde periode waarmee kunst of geschiedenis in zijn algemeenheid onlosmakelijk verbonden zou zijn. Wat de geschiedenis is in een bepaalde periode is niet altijd even duidelijk. Het gevolg is bijna een singulier lineaire benadering van de schilderkunst met uitsluiting van alles wat niet in deze denkbeeldige lijn van ontwikkeling past. Het hoofdstuk over landschapsschilderkunst in de publicatie van Lesbre en Liu is een perfecte illustratie van deze benadering. Natuurlijk heeft deze benadering waardevolle inzichten opgeleverd en bovendien is ze zeer nuttig voor het dateren en attribueren van schilderijen. Maar schilderkunst is zoveel meer en er valt zoveel meer te vertellen over schilderijen dan alleen stijlontwikkeling. Zo blijft het hele idee waarom landschapsschilderkunst nu zo belangrijk is en wat Chinezen daar eeuwenlang en nog steeds in zien, volkomen in nevelen gehuld, afgezien misschien van een verwijzing naar het belang van bergen in het daoïsme.

Een thematische aanpak omzeilt deze beperkingen en al naar gelang het gekozen thema kan zonder belemmering door het opgelegde historische perspectief vrijelijk ingegaan worden op door de auteurs gekozen aspecten in de Chinese schilderkunst die ook nog eens geïllustreerd kunnen worden met voorbeelden. Binnen de verschillende thema's kan er nog steeds een historische ontwikkeling gevolgd worden maar onafhankelijk van stijl of biografieën van beroemde schilders. Misschien als toelichting: zowel een historische als een thematische benadering zijn waardevolle manieren om naar kunst te kijken en horen elkaar aan te vullen. Het verschil in benadering is bij wijze van illustratie ook te zien in de inrichting van musea. Het British Museum volgt bijvoorbeeld een historische indeling, terwijl het Victoria \& Albert Museum een thematische organisatie van de collectie beoogt. 
gevolg van een historische indeling, eentje die wellicht bedoeld is vanuit het oogpunt van de opdrachtgever (het museum dan wel de staat) is dat door een lineair verband te leggen tussen kunstobjecten uit het verre verleden en die van het heden, de bezitter ervan in feite de rechtmatige opvolger van een bepaalde traditie wordt en deze legitimiteit ook zou kunnen uitstralen naar de rest van de wereld. Deze aanname mag vreemd klinken in onze moderne wereld, maar dit idee ligt ten grondslag aan de keizerlijke kunstcollecties van het oude China. Deze verzamelingen vervulden een dergelijke legitimerende rol en werden niet voor niets in 1949 door de republikeinen mee genomen naar Taiwan na de overwinning van de communisten op het vasteland. Zij zorgen nu voor een paradoxale situatie met betrekking tot de legitimiteit van het 'echte' China. Ook bij het British Museum in Londen en het Metropolitan Museum in New York met hun collecties aan kunst uit de hele wereld spelen soortgelijke ideeën over de legitimiteit van hun wereldse autoriteit een rol. Deze ideeën waren zeer normaal in voorgaande eeuwen maar zijn aan kritiek onderhevig, niet alleen vanuit de wetenschappelijke wereld maar vooral uit de hoek van de verwaarloosde of niet erkende 'ander' (other, subaltern). In 'grote' zin zijn dat onderdrukte volken, minderheden, vrouwen en arbeiders, en in kleinere zin - in de Chinese schilderkunst - het werk van professionele schilders zoals kunstenaars die muurschilderingen vervaardigden.

Een thematische aanpak ondermijnt deze ideevorming over legitimiteit en autoriteit. Hoewel het overgrote deel van de schilderijen gepubliceerd in $\mathrm{La}$ peinture chinoise uit Chinese musea afkomstig is, is er door het ontbreken van een historisch kader geen sprake van een poging van de communistische regering (in samenwerking met de Franse) om een legitieme opvolging te claimen. Het moderne China lijkt in dit opzicht definitief gebroken te hebben met haar verleden. Dit kan wederom geillustreerd worden met het voorbeeld van een museum, of liever gezegd het ontbreken ervan. China heeft bijvoorbeeld geen 'Groot Communistisch Museum van het Volk' in Beijing, als een soort onverzettelijk monument van haar macht en legitimiteit. Het museum in de tamelijk lege Verboden Stad (de kostbare inhoud ligt immers in Taiwan) wordt juist door haar ambiance geportretteerd als een restant uit het feodale verleden waarvoor geen duidelijke plaats is in het huidige China (misschien na hereniging met Taiwan?).

Dit roept misschien vragen op over de identiteit van het moderne China, maar de auteurs van La peinture Chinoise kunnen dankzij deze afwezigheid van een ideevorming over legitimiteit ruimschoots aandacht geven aan onderwerpen waarvoor vroeger geen duidelijke plaats was in de geschiedenis van de Chinese schilderkunst, zoals portretten van vrouwen, zedenschilderijen en religieuze kunst. Ook staat deze aanpak toe de verbanden tussen de verschillende thema's beter toe te lichten alsmede de diversiteit van de schilders, die niet altijd aan het stereotiepe beeld van de literatenschilder beantwoorden. Bovendien is door het stilzwijgend afschaffen van het dualisme tussen literaten- en professionele schilderkunst een heel nieuw spectrum van mogelijkheden voor nieuw onderzoek geopend en daarmee het opnieuw aanschouwen van de Chinese schilderkunst. Ten slotte is het door de renovatie van vele tempelschilderingen en het openen van vele graftombes met daarin muurschilderingen of meebegraven rolschilderingen mogelijk geworden om veel schilderkunst in een duidelijker perspectief van de toenmalige visuele praktijken te plaatsen.Dit roept $t_{-0}$ nieuw $\mathbf{w}_{4}$ nieuwe $02: 01: 32 \mathrm{PM}$ verbanden en extra diversiteit op. 
Door een werk van dit formaat en niveau te presenteren als La peinture chinoise is het onvermijdelijk dat daarmee een standaard wordt vastgesteld en zodoende wordt de Chinese schilderkunst opnieuw gedefinieerd. La peinture chinoise is op dit moment een van de meest complete en uitvoerige werken op het gebied van de Chinese schilderkunst en behandelt zeker een groot aantal, maar niet alle aspecten. Door te kijken wat ontbreekt, is het mogelijk een inzicht te krijgen in de visie van de auteurs (en hun sponsors, de Chinese en Franse staat) op de Chinese schilderkunst.

Ongeacht mijn eerdere kwalificatie dat door een thematische aanpak alle sociale gelederen aan bod komen, is La peinture chinoise toch hoofdzakelijk een verzamelwerk gebaseerd op masterpieces en blijft de anonieme, professionele schilder bijna nog steeds zo verwaarloosd als voorheen. Het enige verschil is dat muurschilderingen in graftombes en tempels wel rijkelijk vertegenwoordigd zijn, ook al zijn alleen de bekendste en meest bijzondere geselecteerd. De keuze van rolschilderingen volgt ook nog steeds die van de grote namen, alleen krijgen we nu minder bekende schilderijen van hun hand te zien, schilderijen die niet in Noord-Amerikaanse musea zijn bewaard maar voornamelijk in Chinese musea. Deze schilderingen kunnen echter nog allemaal als meesterwerken worden gekwalificeerd. Wat ontbreekt, is dus misschien een hoofdstuk over de werken van de iets 'professionelere' en daarmee populistische schilders. Men kan denken aan nieuwjaarsprenten, schilderkunst op porselein, of de duizenden schilderijen met 'gedetailleerde' afbeeldingen die in de musea opgeslagen liggen. Natuurlijk spelen esthetische aspecten en wellicht een zekere mate van prestige een rol in de keuze van de thema's en schilderijen, en men is vanzelfsprekend eerder geneigd het beste werk uit een bepaalde collectie te tonen. Zulke keuzes roepen toch de vraag op of dit boek misschien toch ook niet bepaalde van de bovengenoemde tendenties bezit.

Een ander aspect dat volledig ontbreekt in de hele beschouwing van de Chinese schilderkunst is het economische aspect. Er is nergens enige verwijzing te vinden naar transacties, de relaties tussen opdrachtgevers en schilders en hoe deze van invloed zijn op het schilderij, de rol van de toeschouwer of koper van het schilderij, noch over de sociaal-economische leefsituatie van de schilder. De literatenschilders waren net zo afhankelijk van inkomsten als hun professionele broeders. Veel van deze economische aspecten zijn pas recentelijk onderzocht (zie bijvoorbeeld James Cahill's The Painter's Practice uit 1994) en voor de literatenschilders was het een taboe om er over te schrijven. Hierdoor is hierover in verhouding maar weinig bekend en de auteurs zouden over dit onderwerp onvoldoende informatie tot hun beschikking gehad kunnen hebben. Het algemene beeld blijft echter bestaan dat Chinese schilderkunst, zoals al eeuwen wordt gesuggereerd door de literaten-critici, los staat van enige economische activiteit.

Hetzelfde argument zou aangehaald kunnen worden bij de technische aspecten van de Chinese schilderkunst. Afgezien van gedetailleerde opsommingen van de verschillende penseelstroken (splash ink, axe cut etc.) in een soort logische stijlontwikkeling blijft de lezer in het ongewisse over hoe schilderijen worden geproduceerd, welke materialen worden gebruikt, wat de verschillen en effecten zijn van de verschillende materialen, hoe een schilder zijn werk opbouwt. Deze aspecten behoren traditioneel tot het domein van de profes $_{-1: 32 \mathrm{pM}}$ sionele kunstenaar waar de (ideale) literatenkunstenaar zich per definitie niet ${ }^{\text {cess }}$ 
mee bezighield en de auteurs hebben waarschijnlijk geheel onbewust deze tratitie voortgezet.

Het is ten slotte frappant om te zien dat de thematische hoofdstukindeling in grote lijnen overeenkomt met die van de Xuanhe huapu, de beschrijving van de keizerlijke schilderijencollectie aan het eind van de Noordelijke Song dynastie (960-1127). Daarin worden de schilderijen ingedeeld (elk in historisch.overzicht) naar religieuze onderwerpen (boeddhistisch en daoïstisch), portretten, paleizen en gebouwen, buitenlandse volkeren, draken en vissen, landschappen, dieren, bloemen en vogels, bamboe, en vruchten. Het kan natuurlijk zijn dat in de loop van de geschiedenis weinig veranderd is in de onderwerpen die geschilderd en verzameld worden, maar het is zeker een interessant gegeven dat na duizend jaar bijna nog steeds eenzelfde indeling wordt gehanteerd. Het is onmogelijk te weten of de auteurs zich bewust waren van de overeenkomst tussen hun werk en de Xuanhe huapu, waarschijnlijk niet, maar aangezien de schilderijen verzameld in La peinture chinoise feitelijk allemaal meesterwerken zijn en nog steeds voldoen aan alle literatenidealen over Chinese schilderkunst, wordt toch in enige mate de suggestie gewekt dat met het album een keizerlijke traditie wordt voortgezet. La peinture chinoise is een nieuwe mijlpaal in de studie van de Chinese kunst en het kan eigenlijk niet ontbreken in het curriculum van elke student van de Chinese kunst of in de bibliotheek van de liefhebber. Het boek is een bijzonder resultaat van een samenwerkingsverband tussen twee getalenteerde kunsthistorici en tussen twee landen, China en Frankrijk, waarvan nu een breed publiek kan profiteren. De lezers worden in staat gesteld kennis te nemen van de laatste ontwikkelingen op kunstgebied, niet alleen in het Engelstalige Westen maar ook in Frankrijk en China. De vele kleurenreproducties van schilderijen in Chinese musea zijn belangrijke aanwinsten in elke verzameling over Chinese schilderkunst en de revolutionaire thematische aanpak zal hopelijk langzaam erkenning vinden als een nieuwe, verrijkende manier om naar Chinese schilderkunst te kijken.

- Emmanuelle Lesbre en Liu Jianlong

La peinture chinoise

Hazan, Parijs, 2004.

480 pagina's, 345 afbeeldingen in kleur

ISBN 2850259225 